refer to a curious instance of oflicial impatience which occurs in it. On the first page is a paragraph which reads thus : "The Board in the first instance, on July 22nd, called for a detailed report by the medical officer of health of the Catherington rural district, with which request, however, he did not comply until August 6th." Had the latter portion of this sentence been stated affirmatively thus, "with which request he complied on August 6th," it would have been a mere statement of the facts. As it stands, however, it is more than this, it implies a censure on the medical officer of health of the Catherington rural district for having taken so long as 14 days to report on a highly complex epidemic. The current Medical Directory states that the medical officer of health of this district receives an annual salary of $£ 10$ for this appointment. I will not enter into the question as to whether such a highly paid official is deserving of the implied censure, but I wish merely to point out that this censure concerning a delay of 14 days is contained in the report of an inspector who received his instructions to report on August 3rd, 1901, and whose report bears the date of May 10th, 1902.

Coventry, Oct. 27th, 1902 .

I am, Sirs, yours faithfully,

E. H. SNELL.
I met with some time ago and which puzzled me considerably. The clinical features closely resembled those described by Dr. F. B Lund. There was a tense cystic swelling on the outer side of Scarpa's triangle which had been diagnosed as a mass of malignant glands. It was, however, clearly cystic and might have been taken for a femoral hernia if it had not been for the femoral artery which was pushed in front and to the inner side of the swelling. The absence of any flexion of the hip or fulness in the iliac fossa negatived psoas abscess. I took it to be some anomalous form of hernia, but on exposing it I found a thick. walled laminated cyst containing what looked like synovial fluid, and pass ng down to the small trochanter; obviously it was an enlarged ilio-psoas bursa. The anterior crural nerve was tightly stretched over its anterior surface, accounting for the pain. The greater portion of the thick sac was dissected away and the wound was drained. I could not find any communication with the hip-joint. When last seen, however, the patient, an elderly man, still complained of a certain amount of pain and stiffness in the hip. As the condition appears to. be rare the above particulars may be of interest.

I am, Sirs, yours faithfully,

Wolverhampton, Oct. 26th, 1902

EDWARD Deanesty.

\section{THE OXIDATION OF SEWER GASES.}

\section{To the Editors of THE LANCET.}

SIRS,-One evening in the garden of Admiralty House, Bombay, I observed the perfume of the moon-flower, a large white convolvulus whose blooms open after sunst t and fade at the first streak of dawn. Its odour is so delicate and so distinct from all others as to announce the opening of the flowers even if they are not within sight. The plant in question was about 15 feet away when I first perceived its odour and on advancing to examine it $I$ observed that the odour was less sensible close to the flowers than at several yards' distance. The air was almost still, but its movement was in the dirf ction of $\mathrm{my}$ first position, away from the plant, and it seemed as if a certain combination with the atmosphere was necessary in order fully to develop the perfume. At a distance of 25 feet in the same direction the odour was not perceptible. This is not the case with the rose and with certain other flowers whose perfume is strongest at a very short distance. My experience with the moonflower reminds me of complaints that were made in Bombay regarding the emanations from a sewer ventilating pipe by people who lived at least 50 yards away from it, although I was assured by the engineer in charge that he had smelt the discharge at the pipe itself and found no perceptible odour. It is also currently believed that much mischief is caused to the public health by inodorous sewer gases, although it is difficult to believe that any of the very mixed gases arising from decomposed sewage can be odourless. All this seems to point to the necessity of a series of experiments on the oxidation of the gases by decomposition arising from drains and sewers. It is generally admitted that contact with the air is all that is required to render them innocuous, and there are already schemes before the public for the more efficient application of the air to the gases. But for practical success there will arise further considerations, such as duration of contact, intimacy of admixture of the ingredients, influences of wind or still air at the outlet, and lastly, the influence of temperature both as a cause and a cure.

$$
\text { I am, Sirs, yours faithfully, }
$$
JOHN WALLACE

Indian Municipal Journal, Bombay, Sept. 20th, 1902.

\section{MASSAGE IN SPRAINS AND DISLOCATIONS. \\ To the Editors of THE LANCET.}

SIRs, - You have been good enough to publish four letters of mine dealing with the treatment of dislocations and sprains by massage and movement. Since my first letter in February, 1898, various authorities have corroborated the soundness of the treatment which I advocated. In fact, I know of at least two books which have been written since that date about the subject. Still, I am afraid that the treatment is not sufficiently known to a great many practitioners.

I have recently had two cases which show the beneficial effect of the treatment. A policeman slipped on the kerb the Ilio-psoas Bursa in THE LANCET of Oct. 25 th, p. 1139,
is the first reference I have seen to a condition which
SrRs, - Your annotation on the Surgical Importance of

\section{THE SURGICAL IMPORTANCE OF THE ILIO-PSOAS BURSA.}

To the Eatitors of THE LANCET.

effect of the treatment. A policeman slipped on the kerb 